\title{
UC Global Food Initiative: UC ANR student fellows work on food insecurity, food communication and developing the next generation of Cooperative Extension experts
}

\section{The UC Global Food Initiative (GFI), launched by UC President Janet Napolitano in July 2014, is a systemwide effort to address food security, health and sustainability through coordinated work across the 10 campuses, UC Agriculture and Natural Resources (UC ANR) and Lawrence Berkeley National Laboratory. The GFI targets food systems at all scales, from the local to the global, and aims to drive changes that will help to sustainably and nutritiously feed a world population of 8 billion by 2025 .}

Among the first programs funded through the GFI was a fellowship program for UC students. In December 2014, Napolitano announced the 54 winners, each of whom received a $\$ 2,500$ stipend. UC ANR's three GFI student fellows have worked on projects this year with researchers or staff in the division.

Jacqueline Chang, who graduated in May from UC Berkeley with a degree in nutritional sciences, helped to carry out a two-pronged study of food insecurity and food environments on the 10 UC campuses.

The project was motivated, Chang said, by the growing evidence that many college students, for a variety of

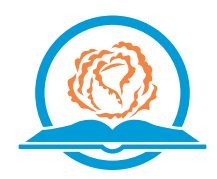

\section{Global Food Initiative}

defines as "limited or uncertain availability of nutritionally adequate and safe foods or limited or uncertain ability to acquire acceptable foods in socially acceptable ways." She worked with Director Lorrene Ritchie and other UC ANR researchers at the Nutrition Policy Institute.

The project included two major parts: A 10-campus survey of students designed to gather data on the prevalence and correlates of food insecurity; and a study of the retail food environment in the vicinity of each UC campus that assessed the quality of the available foods.

Chang presented results from the food environment study at a conference of GFI fellows in July. Nutrition Policy Institute researchers are continuing to analyze data from the 10-campus survey. During her undergraduate years,
Chang was involved in several food security initiatives on the UC Berkeley campus and in the city of Berkeley. She is currently working at a health clinic in Los Angeles through Community HealthCorps, an AmeriCorps-funded program.

Samantha Smith, a graduate student in public health sciences at UC Davis, used her GFI fellowship to interview UC scientists about their research and extension efforts in agriculture, food and nutrition. The objective, she said, was to tell the stories of "people who have been notorious for not tooting their own horns."

Working with Constance Schneider, UC ANR's Youth, Families and Communities Director, as well as UC ANR Public Information Representative Jeannette Warnert, Smith wrote six profiles that are now featured in the "Stories from the field" section on the UC ANR Global Food Initiative website.

"There will never be a time when having writing skills is not going to be useful," said Smith, who learned of the GFI fellowship opportunity in a communications course during the Fall 2014 quarter. Smith completed her MPH degree in September and is currently working with a group developing a smartphone app related to personal sexual health and safety.

Kevi Mace, a doctoral candidate in the Department of Environmental Science, Policy and Management at UC Berkeley, used her GFI fellowship to expand her ongoing work to raise awareness about career opportunities in Cooperative Extension (CE) and help graduate students develop skills for CE work.

Many graduate students are interested in doing applied science but don't know much about CE, Mace said. "If you don't know what it is, it's hard to go about preparing to do extension," she said.

Mace grew up in rural Colorado and is a 4-H alum. In 2014, she was a member of the first cohort of graduate students funded through a 3-year UC ANR pilot, the Graduate Training in Cooperative Extension program. CE-specific training through the program includes workshops on outreach to non-scientists, communicating with people outside one's field and writing effective policy briefs.

Mace's fellowship, with UC ANR Program Policy Analyst Vanessa Murua, supported her work in helping to host this year's CE showcase, an annual outreach event for students on the Berkeley campus in February. CA

- Jim Downing 